\title{
Fear of Negative Evaluation, Loneliness and Life Orientation of Never Married Men and Women
}

\author{
Sadia Yasmin \\ University of Lahore, Lahore, Pakistan \\ Sadia Firdous \\ University of Lahore, Lahore, Pakistan \\ Sheeba Saqib \\ University of Punjab, Lahore, Pakistan \\ Tahira Khatoon \\ Nursing Superintendent Nawaz Sharif Hospital, Lahore, Pakistan
}

\begin{abstract}
The purpose of the present study was to assess the relationship among fear of negative evaluation, loneliness and life orientation among never married men and women. It was hypothesized that there would be a significant relationship among these variables and there would be gender differences among the participants. Correlational research design was used. The sample size of the study was 200 including 100 males and 100 females selected using purposive sampling. Correlation, regression, independent sample $\mathrm{t}$ test and mediation analysis were used. Findings showed that fear of negative evaluation is significantly and positively related with loneliness and negatively related with optimistic life orientation. In addition, loneliness significantly predicted optimistic and pessimistic life orientation. There were also significant gender differences among participants on loneliness and optimistic life orientation. In addition, it was found that loneliness significantly mediated the relationship between fear of negative evaluation and life orientation.
\end{abstract}

Keywords: Fear of negative evaluation, loneliness, life orientation, optimism, pessimism.

DOI: $10.7176 / \mathrm{JHMN} / 71-05$

Publication date: February $29^{\text {th }} 2020$

\section{I.INTRODUCTION}

In the span of the recent decades, major transformations and changes have been seen in the population. One of these changes is increase in the number of never married or single adults. According to some recent estimates, there are more than 80 million unmarried adults living in America alone. For UK, the numbers span to about 20 million.

The numbers have been rising since the span of the 1980s due to a wide range of factors including the need for economic independence, lack of trust in relations, lack of access to suitable partners, changes in life aspirations and goals etc. (Andersson, 1996; Badoux \& Mendelsohn, 1994; Chen \& Feeley, 2015). Some research has shown that never married individuals tend to have a higher sense of wellbeing and purpose in life (Andersson, 1996; Badoux \& Mendelsohn, 1994; Chen \&Feeley, 2015). However, the contrasting findings on this area are large. However, it needs to be understood that there is a gap in literature when it comes to assessing the psychological domains of never married men and women.

It is critical to note that despite of the appeal of remaining single and leading a life free from certain responsibilities, there are a number of negative sides to not being married. The research on this area is growing and has been pivotal in providing numerous insights about this domain.

\section{Research Background}

Studies on fear of negative evaluation, loneliness and life orientation among never married men and women had started in the 1970s and 1980s. A number of researchers were interested in terms of assessing the differences in the psychological strengths and traits of individuals who are married in comparison to those who are unmarried (Andersson, 1996; Badoux \& Mendelsohn, 1994; Chen \& Feeley, 2015). Also, research has been done to explore the psycho-social determinants of the phenomenon of remaining single. It is well known among older and younger people that the presence of a spouse is termed an important source of emotional and physical wellbeing. Some researchers argue that the beneficial effects are mainly seen due to the social integration function played by marriage (Monzani, Steca \& Greco, 2014; Vecchoine, Alessandri, Caprara \& Tisak, 2014).

However, most recently, interest in this area has re-emerged primarily due to the need of conducting comparative assessments among never married individuals and to investigate their meaning and purpose in life and their experience of loneliness. It has been found that the presence of an individual facilitates one's level of 
social interaction and is important for the purpose of building companionate relations (Vecchoine, Alessandri, Caprara \& Tisak, 2014).

Other important functions of getting married include: protection, security, reproduction, social support, sharing one's burden, having a meaning and purpose in life, going beyond the needs of the self, leaving behind one's progeny and a lot more. However, it should be noted that these functions and benefits are not wholly important for all individuals. Most recent evidence has shown that for a large number of individuals, the integrating role of marriage and the stereotypes associated with never getting married are not important. For them, pursuing one's professional goals and dreams is more important as for a number of individuals marriage is often a barrier towards the achievement of these goals. Also, marriage is understood as being a form of social connectedness that helps individuals to become associated with the society (Andersson, 1996; Badoux \& Mendelsohn, 1994; Chen \& Feeley, 2015).

There are a number of studies that have assessed the relationship between social connectedness and loneliness among never married individuals. Golden et al. (2009) had reported that social connectedness and loneliness can be linked with negative consequences in terms of mood and wellbeing. The data for the study was collected from a university in Dublin. The results had shown that social connectedness negatively predicted loneliness. Also, a negative relationship was reported between the two constructs i.e. social connectedness and loneliness. It was also found that the mental health consequences of both problems can range in the short to long run.

Singh and Mishra (2009) had assessed the relationship between depression, loneliness and social connectedness. The results had shown that there is a positive association between loneliness and depression. On the other hand, social connectedness was reported as being negatively associated with depression. The findings have shown that social connectedness can be beneficial in terms of overcoming the negative consequences of different psychological conditions. The research on this area has also shown that both constructs predict each other. In other words, the direction of the relationship between the two is marked by reverse causality (Monzani, Steca \& Greco, 2014; Vecchoine, Alessandri, Caprara \& Tisak, 2014).

In order to explore this area in a detailed manner, it is critical to first define the constructs that are important for this investigation.

\section{Fear of Negative Evaluation}

The emotional response to danger or threat is called fear (House \& Stark, 2002). It works as a basic mechanism for existence when a specific or dangerous stimulus is presented. This can be maladaptive at times (Robinson, 2010). Fear can affect the life of a person and weakens him internally. Every person has to experiences some type of fear in his life. It may range from the fear of darkness to the fear of death. The maladaptive form of fear is called phobia that can be of some specific thing, person, place, situation or it can be of more general form (Stephan, Stephan, \& Palmer, 2008). One is type of fear is fear of negative evaluation (FNE) that means the sense of terror and anxiety related to be negatively evaluated by people while participating or expecting any social situation (Weeks \& Heimberg, 2005).

Social situation is the core aspect of FNE and as humans we are social animals, Man lives in the web of social relations that mostly consists of parents, siblings, relatives, friends, neighbors, coworkers and many more. An individual leads a happy life as long as these relationships remain healthy and the health of such social relations depends on the way of communication with others. This communication or, in other words, expression of oneself can be inappropriate due to various reasons. One reason of it can be the fear of individual that he might not express himself in appropriate manner and people will judge him in a negative way (Karabulut, Bahadir, Certel, \& Pulur, 2013).

Fear of negative evaluation was first explored and defined by Watson and Friend (1969). It is defined in terms of the apprehensions, distress, anxiety and the expectations about being viewed and evaluated in negative terms by members of the society (Monzani, Steca \& Greco, 2014; Vecchoine, Alessandri, Caprara \& Tisak, 2014).

It is also defined as the persisting levels of feelings and thoughts about being rated and viewed negatively by other individuals. It is critical to note that the researchers on this area have classified FNE in relevance to a number of core dimensions including anxiousness, submissiveness, social avoidance, social rejection and social introversion. Another definition of FNE is the need to get attention and positive appraisal from others. Research has shown that individuals who score high on this construct are always in search of social approval and cannot tolerate the feelings of disapproval from other individuals (Andersson, 1996; Badoux \& Mendelsohn, 1994; Chen \& Feeley, 2015).

In a nutshell, fear of negative evaluation (or FNE) is a fear of criticism and an inability to cope with anyone thinking badly of you. You might know on one level that it's not possible for everyone to like you, but you might still find it really hard to cope with not being invited to a party or being ignored by an acquaintance.

\section{Theoretical Framework on Fear of Negative Evaluation}

There are a number of theories that have been developed in relevance to this construct. 
Reiss's Expectancy Theory

Reiss (1991) proposed a model to explain fear. This model has been widely researched and it suggests that motivation of a person to avoid fear situation is based on two components: expectancy and sensitivity. Expectancy refers to the parson's expectations regarding the particular feared situation while sensitivity means theoretical tendency of a particular stimulus to elicit expectations to feel fear or anxiety.

Reiss (1991) identified six factors related to fear, including, injury sensitivity, danger expectation, anxiety sensitivity anxiety expectation, social evaluation sensitivity and social evaluation expectation. In all these components, social evaluation expectation refers to the expectancy that how the person will feel and behave in a particular social situation or for a feared stimulus. On the other side, social evaluation shows that how much a person is sensitive to social situations during interaction with others.

In more general form Reiss (1991) described that there are three major fears that falls under the umbrella of total fear behavior. The three fundamental fears of Reiss are of negative social evaluation, death/illness and anxiety sensitivity. All of these are product of expectations and sensitivity.

Reiss (1991) proposed that fear of negative evaluation consists of three parts.

i. $\quad$ First is to experience a feeling of discomfort, distress, anxiety and fear in social states.

ii. Second is the deliberate effort to avoid such social situations.

iii. Third is the feeling of apprehension to get negative evaluation by others.

\section{Self-regulation Theory}

Second is the self-regulation theory. This theory represents a system of consciousness personal control and management that is concerned with the process of guiding one's thoughts, emotions, beliefs and feelings for the purpose of reaching goals (Vagos, Salvador, Rijo, Weeks \& Heimberg 2016).

It also involves an internal and external assessment about oneself with the need to gain control over the different problems in life. Apart from this, self-regulation is concerned with fear of negative evaluation. It is mainly because of the notion that self-regulation is seen in terms of the fear of negative evaluation. Individuals who score high on self-regulation are able to control and adjust their feelings about one and about others as well as their thought processes in order to remain functional. On the other hand, individuals who score low on self-regulation are more prone towards experiencing feelings of apprehension and anxiety as well as the fear of being evaluated in a negative manner (Vagos, Salvador, Rijo, Weeks \& Heimberg 2016).

\section{Rapee and Heimberg's Cognitive-behavioral Model.}

Rapee and Heimberg's model (1997) provide extensive detail about the mechanism of social fear and anxiety. They consider FNE an important aspect of social anxiety. Socially anxious individuals have high levels of fear about being assessed by others and in result avoid such social situations.

According to Rapee and Heimberg (1997) a person having social anxiety perceives others as critical who have high standards of judgment. He develops an image that how others will see him and analyze him. Then he compares his performance and social skills with his expected standards of others. When he finds difference between his social performance and perceived standards of people. He expects critical evaluation from them. And thus he starts fearing that other people will judge his performance and him critically and negatively. This results in feelings of discomfort, distress and anxiety. To avoid such feelings and thoughts he tries to avoid such situations.

\section{Causes of Fear of Negative Evaluation}

Healthy Communication in a society is a key factor that is important for psychological health of a person. Researchers have explored that it plays an important part in developing social identity and determining the behavior of individual within a society. (La Greca \& Lopez, 1998; Nurmi, 2004).

It is considered that unhealthy communication patterns result into unhealthy relations and these unhealthy relations in transition periods pave path for fear of negative evaluation and social anxiety. A person always wants approval and appreciation for his work from others. The non-healthy relations create a sense of negativity in individual and he might develop a fear of rejection and fear that he might be negatively judged by others (Albano \& Hayward, 2004).

Generally, various studies have indentified that different factors contribute in the occurrence of FNE and social anxiety. Some important factors include genetics, social skills, social norms, peers relationship, cognitive biases, temperament and conditioning experiences (Teachman \& Allen, 2007).

Researches explain that socialization is basically a comparative procedure. Individuals evaluate their own behaviors comparative to societal norms. Once an individual realizes that he is doing or saying wrong things, which are not according to the norms he readily leads towards negative evaluations of one's social success. Comparing oneself by societal norms particularly yields numerous opportunities for negative self-evaluation (Dunbar, 2004). 
Gender Based Manifestation of Fear of Negative Evaluation

It is also an important question that whether women experience more FNE or men. La Greca and Lopez (1998) found the answer of it and described that women exhibit high levels of FNE as compare to men. Girls reported to have fear of negative evaluation specifically from their peers. Miller (1995) found that women have more evaluative anxiety and high motive to avoid rejection. Few studies have also explored the relation of FNE with age. In one study on Spanish adolescents, Garica-Lopez, Olivares, Hidalgo, Beidel, and Tuner (2001) found that the trend of FNE increased with the growing age.

\section{Loneliness}

Every person needs some time to be alone during which personality development and creative activity may take place. When being alone becomes painful and distressing for a person it refers to the state of loneliness. Social psychologists especially take interest in the phenomena of loneliness because it represents a subjective state of discrepancy between actual and perceived relationships (Berg \& Peplau, 1982).

Loneliness is viewed as a complex emotional response to isolation. The lack of social bonds and the lack of interpersonal relations trigger this emotional response (Leary, 1990). It is also defined as a construct that is seen at times when there is a lack of connections and communication among individuals. It is a complex emotional and psychological state that is marked by the discrepancy between one's achieved and desired levels of social interaction (Badoux \& Mendelsohn, 1994). Thus, it can be said that the loneliness is somewhat different from social isolation. It is also defined as a complex psycho-physiological state which encompasses lack of proper social connection, insufficiencies in interpersonal domains, the inability to bond with someone and the inability to feel connected (Lee \& Robbins, 1995).

Another perspective defines it as a transient state in which an individual becomes disconnected with the environment and tends to focus his or her energies towards the inside while feeling inadequacies in achieving proper social functioning. It can also be defined as a subjective experience marked by social isolation (Crick, Grotpeter \& Rockhill, 1999).

Inherently, humans are social animals and no one can live alone. When people are asked to rate the things which are most pleasurable and bring happiness in their life, majority of them choose intimacy, companionship, and social affiliation over money, power, and even physical health. It shows how important social connection is in man life; at same time it is alarming that proximately $20 \%$ of American population state the feelings of social isolation as the major source of unhappiness (Cacioppo \& Patricks, 2008).

Psychologists have recently started the essential task of discovering factors that contribute to the development and maintenance of loneliness. Feelings of isolation and detachment from others have been observed to have a host of negative correlates, including, depression, anxiety, self-derogation, hostility and feelings of hopelessness (Russell, Peplau, \& Ferguson, 1978; Horowitz \& de Sales French, 1979, Russell, Peplau, \& Cutrona, 1980; Ahmed, 2013).

\section{Types of Loneliness}

Some important types of loneliness are given below.

\section{Interpersonal Loneliness}

Interpersonal loneliness occurs when a person loss a very close person with whom he remained attach. This loss can be in the form of temporary separation or in the form of permanent separation (Buswell, 2013).

\section{Social Loneliness}

Social loneliness arises when a person is disqualified or rejected by a group due to a number of reasons which creates a sense of being rejected, unworthy and lonely (Buswell, 2013).

\section{Intellectual Loneliness}

Intellectual loneliness occurs when a person is not equal in education or educationally lowers than his friends or peer group. It can also be occur when a person feels incompetent among his siblings and starts feeling him intellectually low (Buswell, 2013).

\section{Psychological Loneliness}

Psychological loneliness is different from other types. It occurs when a person experience a traumatic event in his life and after that event the person starts feeling himself different from others and considers that he is the only one who experienced this. It separates him from others and this state is not understandable because it is internal state (Buswell, 2013). 
Existential or Cosmic Loneliness.

Existential or cosmic loneliness is related to death. When a person is near to death due to chronic disease or a person face the death of loved one, it creates a sense of loneliness in this person. The fear of being dead or loss someone socially isolates that person who experienced it (Buswell, 2013).

\section{Theories of Loneliness}

One theory of loneliness posits that perceived social isolation is tantamount to feeling unsafe, and this sets off implicit hypervigilance for (additional) social threat in the environment. Unconscious surveillance for social threat produces cognitive biases: relative to nonlonely people, lonely individuals see the social world as a more threatening place, expect more negative social interactions, and remember more negative social information. Negative social expectations tend to elicit behaviours from others that confirm the lonely persons' expectations, thereby setting in motion a self-fulfilling prophecy in which lonely people actively distance themselves from would-be social partners even as they believe that the cause of the social distance is attributable to others and is beyond their own control This self-reinforcing loneliness loop is accompanied by feelings of hostility, stress, pessimism, anxiety, and low self-esteem and represents a dispositional tendency that activates neurobiological and behavioural mechanisms that contribute to adverse health outcomes (Cacioppo et al., 2006).

Some other theories of loneliness are as follows:

\section{Psychodynamic Models}

A psychodynamic understanding of loneliness is based on the infant's attachment to the mother. Through this attachment the child experiences emotional bonds and how to connect with others, but also the feeling of loneliness when significant others are out of sight. Loneliness, which is the exceedingly unpleasant experience connected with inadequate discharge of the need for human intimacy, for interpersonal intimacy. It begins in infancy with an integrating tendency that we only know by inference from pathology material late, a need for contact with the living (Sullivan, 1955).

\section{Roger's Phenomenological Perspective}

Roger (1961) explains loneliness in the context of his "self theory". He explains that loneliness occurs when a person thought that his real self is unloved or rejected from society. These thoughts and fear keeps peoples to have an empty sense of self and to be locked in their loneliness. (Roger, 1961).

\section{The Existential Approach}

An existentialistic understanding of loneliness also differentiates between different kinds of loneliness, the main one being existential, meaning there is loneliness that is part of the human condition, but also another one based on anxiety. Existential loneliness is an intrinsic and organic reality of human life in which there is both pain and triumphant creation emerging out of long periods of desolation. In existential loneliness man is fully aware of himself as an isolated and solitary individual while in loneliness anxiety man is separated from himself as a feeling and knowing persons

(Moustakas, 1961).

\section{The Interactionist View}

An Interactionist approach is based on loneliness being multidimensional, meaning that there are different kinds of loneliness, including emotional- and social loneliness. Loneliness is caused not by being alone but by being without some definite needed relationship or set of relations... In many instances it is a response to the absence of provision of a close, indeed intimate, attachment. It also may be a response to the absence of the provision of a meaningful friendship, collegial relationship, or other linkage to a coherent community (Weiss, 1973).

\section{The Cognitive Approach}

The cognitive approach is based on a discrepancy model between desired- and actual social relations. This approach shows that loneliness is a response to a discrepancy between desired and achieved levels of social contact and that cognitive processes, especially attributions, have a moderating influence on loneliness experiences. (Peplau \& Perlman, 1982).

\section{General System Theory}

General system theory says that loneliness is the feedback of our internal mechanism for making optimal social contacts that is useful for the wellbeing of society and individual (Flader, 1982).

\section{Loneliness as a Social Deficiency}

Social deficiency theory states that isolation is a form of social deficiency. It results due to a number of personal, 
affective and behavioral personality traits and manifestations. These traits and measures serve as predisposing and precipitating factors that contribute to the development of this emotional state. All individuals have a tendency to increase their level of social contact and to minimize the effects of social deficiencies. Also, an individual's attribution style whether internal or external shapes his or her tendency to experience loneliness. The theory also states that loneliness should be viewed as an outcome rather than a causal factor itself. It has been argued that the lack of social relations, the inability to share one's life with others, the inability to form close relations, psychological problems and other related factors contribute to the development of the loneliness (Peplau \& Perlman, 1979).

Hawkley (2010) had also proposed a theory of loneliness. Human beings are thoroughly social creatures. Indeed, human survival in difficult physical environments seems to have selected for social group living. Consider that the reproductive success of the human species hinges on offspring surviving to reproductive age. Social connections with a mate, a family, and a tribe foster social affiliative behaviors (e.g., altruism, cooperation) that enhance the likelihood that utterly dependent offspring reach reproductive age, and connections with others at the individual and collective levels improve our chances of survival in difficult or hostile environments (Monzani, Steca \& Greco, 2014; Vecchoine, Alessandri, Caprara \& Tisak, 2014).

These behaviors co-evolved with supporting genetic, neural, and hormonal mechanisms to ensure that humans survived, reproduced, and cared for offspring sufficiently long that they, too, could reproduce. Human sociality is prominent even in contemporary individualistic societies.

\section{Discrepancy Model of Loneliness}

Perlman and Paplau in 1998 developed discrepancy model of loneliness. Although the experience of loneliness is different for each individual but common elements in loneliness can be identified. Figure 1 presents a model for understanding loneliness and the phenomena associated with it. Central to this discrepancy model is the idea that loneliness occurs when there is a significant mismatch between a person's actual social relationships and his or her needed or desired social relations.

A man who longs to be married but who is still single will feel lonely. Loneliness theorists differ in how they conceptualize the nature of this discrepancy.

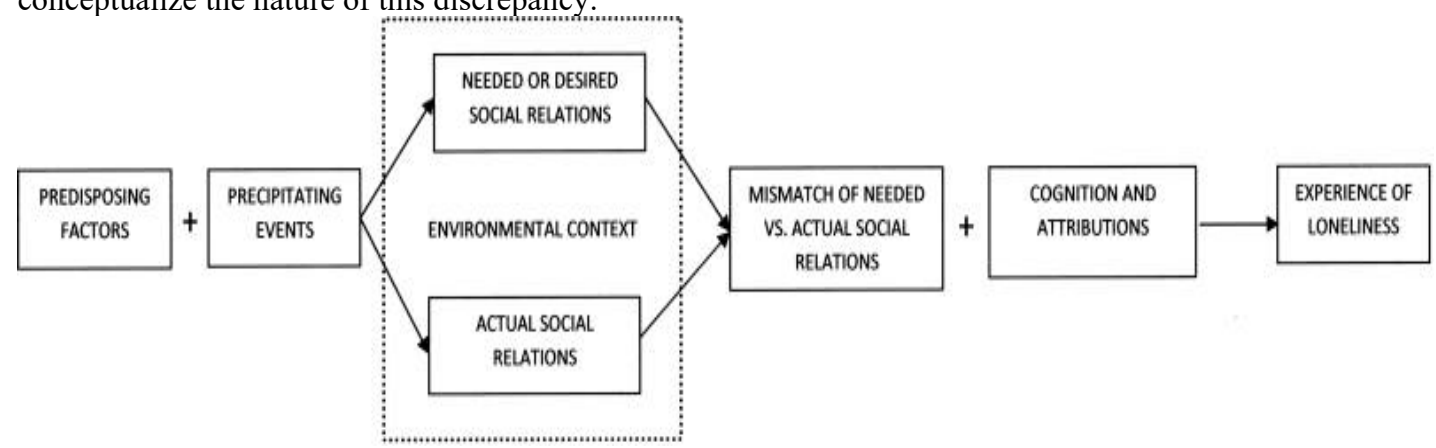

Fig.1 Discrepancy Model of Loneliness

The model in Fig. 1 also includes the more distal antecedents of loneliness, distinguishing between predisposing factors that make people vulnerable to loneliness and precipitating events that trigger the onset of loneliness. Diverse predisposing factors can increase a person's risk of loneliness. Individual differences in personality and behavior such as extreme shyness or the lack of social skills may interfere with creating or maintaining satisfying social relationships and thereby set the stage for loneliness.

\section{Factors Contributing to Loneliness}

Cicioppo and Patrick describe (2008) factors of loneliness and it help to understand because feelings of lonely people are combination of three factors.

\section{Vulnerability to Social Disconnection}

A human being has many instincts and has a different genetic inclination for certain things. Like every person has different standard and need for social connection. Some people are more social than others. If a person have high tendency for social connection, there are many difficulties to fulfill that need which results into loneliness (Ciccioppo \& Patrick, 2008).

\section{Ability to Regulate the Emotions Associated With Feelings of Isolation}

Everyone has an innate need for social connection, if that need remain unfulfilled; it causes distress to person. The person starts to remain alone, remain detach from social gatherings. If this isolation continues for long time it 
becomes a cause of upset mood for the person who is experiencing it.

Then this constant sad mood leave negative impact on person and he became unable to access correctly other people concerns for him. The person perceives other people are distant from him and they do not care for him. But it is only because of his wrong perception (Ciccioppo \& Patrick, 2008).

\section{Mental Representations as Well as Expectation and Reasoning about Others}

It does not mean that the person who is feeling lonely has lack of social skills. But when a person feels lonely, this feeling stops him to use that skill. He perceives that he is unable to start or maintain relationships as well as what he doing for others is useless and other are not responding his efforts. This causes frustration in him and result in low mood. He started blaming himself or others if someone disapproves his act (Ciccioppo \& Patrick, 2008).

\section{Life Orientation}

Life orientation defines as the tendency to view and interpret the events in life in positive or negative terms. In other words, it stands for an individual's disposition and learned responses to exhibit an optimistic or pessimistic approach towards life. Research has shown that life orientation can be better understood in relevance to dispositional optimism. It is viewed as the positive psychology construct that is inborn and contributes towards the wellbeing and psycho-social functioning of individuals (Monzani, Steca \& Greco, 2014; Vecchoine, Alessandri, Caprara \& Tisak, 2014).

It has also been found that life orientation encompasses social support, optimism and life satisfaction. It is critical to note that life orientation of an individual has a considerable amount of impact on the psychological wellbeing and life satisfaction among individuals. Another definition of life orientation is that it is the explanatory style (positive vs. negative) that an individual uses in relevance to the different areas of life. Apart from these definitions, life orientation has been studied in relation to the attribution styles of individuals which can be internal or external (Monzani, Steca \& Greco, 2014; Vecchoine, Alessandri, Caprara \& Tisak, 2014).

An individual's overall outlook about life and perception regarding different events, fortunes and misfortunes of life is termed as life orientation. Optimistic individuals have positive outlook about perceptions regarding their life. Individuals experiencing positive life orientation tend to be more happy, contended and physically and psychologically healthy while the individuals with negative life orientation experience tough, stressful, perplexing and less contented life (Dean, 2011).

The empirical evidences prove that optimistic people are happier, strong and more contented than pessimistic individuals. Optimistic individuals are characterized problematic life events as temporary, situational, limited in its effects and not entirely their fault. Pessimistic individuals consider the problematic life events as rather permanent, difficult to overcome (Khan, 2006).

Optimism is a generalized positive expectation for occurrence of good things in almost all cases (Seligman, 2007). Scheier and Carver (1992) describe optimism as tendency of expecting the best. According to Turkum (2001), optimism is the basic tendency for perceiving positive rather than negative cases.

Optimism is evaluated as an important way for having positive feelings for life, high morale, determination, effective problem solving, academic, military and vocational success, being popular, healthy long life, and getting rid of depression and trauma (Seligman, 2007).

Pessimism is accepted as a reflection of depression, passiveness, failure, social incompetency, illness and death (Seligman, 2007).

\section{Types of Life Orientation}

There are two types of life orientation i.e. optimism and pessimism.

\section{Optimism}

Optimism has been defined as hopeful cognitive pattern characterized by the anticipation of achieving positive outcome ( Scheier \& Carver, 1985).

They tend to expect positive and healthy future despite problems in present life. They tend to use positive explanatory style for previous life events. They believe that they are responsible for leading appositive life in present and in future. They Aram high and tend to respond appropriately at positive outcomes (Dean, 2011).

Khan (2006) stated that optimism has a strong relationship with other positive qualities and aspects of life. Optimists tend to experience higher wellbeing, resilience, positive emotions, healthy and adaptive stress management, achievements, adjustment and physical healthy. Their coping with trauma leads to positive and healthy outcomes and they experience more positive emotions afterwards. Optimistic people experience less health issues. The rate of heart and cardiovascular issues is lower in such people.

\section{Pessimism}

Second type of life orientation is pessimism. Pessimistic individuals tend to generally think of negative outcomes 
and perceived present problematic situation in a negative way ( Scheier \& Carver , 1985).

Their negative thinking madness healthy coping and stop them from actively engaging in actions that yield positive results (Khan, 2006). They are higher risk of developing chronic illnesses and mortality rate is also higher in pessimists. According to previous alliterative hypertension, anxiety and depressive symptoms are common in such people (Dean, 2011).

\section{Characteristics of Optimistic Individuals}

Optimists are thankful for the blessings they already have. According to Alan Loy McGinnis tough-minded optimists usually predict outcomes in positive way tend to find out constructive solutions to the problems which lead to positive outcomes. They 'control their future and fate'. Even during the darkest hour, they cannot stop imagining success. They explore themselves and believe in self- actualization and tend to reach their maximum level of potential. Optimists believe in love. They are more likely to accept what cannot be changed rather than falling in denial (Trathen, 2015).

\section{Characteristics of Pessimistic Individual}

Pessimistic tend to be less happy despite having less troublesome life. They always find mistakes and negativity in different things. They do not even ignore minor mistakes and also cannot speak about their problems. Future apprehensions regarding health and fear of being sick make it difficult for them to enjoy their present status of health. They always expect that bad would happen. They even believe that good will always happen with an aversive outcome. They are less thankful for what they have got and often complain about the poor past (Trathen, 2015).

\section{Life Orientation Theories}

There are few life orientation theories which are discussed below.

\section{Relational Regulatory Theory of Interpersonal Support}

This theory has been designed to assess the perceived effects of social support and mental health for never married individuals and also for those individuals who have been abandoned by their families. It has been found that perceived social and interpersonal support has direct effects on the mental health of individuals who are never married (Monzani, Steca \& Greco, 2014; Vecchoine, Alessandri, Caprara \& Tisak, 2014).

The relationship is mediated by individuals who are required to regulate their emotions through ordinary and shared conversations. In order to cope with stress, they should be able to achieve effective regulation of their emotions. In case of non-regulation or lack of regulation, individuals tend to experience negative psychological consequences such as hopelessness, isolation, stress, depression etc. The main mechanism explaining the association is relational in nature. In other words, the factors identified in the theory are dependent upon one another (Lakey \& Orehek, 2011).

\section{Attachment Theory}

This theory states that all humans desire some form of attachment. This need is developed since the time of birth and continues to evolve with the development of individuals. Research has shown that the kind of attachment styles individuals form in their childhood continue to influence their attachment orientations in their adulthood (Goldberg, Muir \& Kerr, 2013; Holmes, 2014).

In this regard, some findings have shown that never married individuals might indicate problems in becoming linked with another person. It might be due to their disruptive attachment styles during childhood, due to lack of availability of a proper partner, due to financial and social constraints etc. It is important to note that loneliness is a depressive and aversive state that results from the inability of becoming connected with someone else and due to the unfulfilled needs of being close to someone or as a consequence of abandonment by another individual. It is also due to insecure attachment styles of individuals due to which they are not able to form, maintain or think about being in a relationship (Goldberg, Muir \& Kerr, 2013; Holmes, 2014).

\section{Expectancy Model of Life Orientation}

Expectancy value models begin with the idea that the behavior is aimed at attaining desired goals (Carver, 2001). Goals are final outcomes that are either desired or undesired. People have to modify their behavior to aim and strive for the desired goals and to avoid the undesired ones. Theoretically, the goal should be realistic and attainable in order to take step in the right direction. The panning to achieve the goals should be realistic. Expectancy means the degree to which the individual believe that the desired goal will be achieved. If they believe is not strong enough, desired action will not be taken by the individual and the goal will not be achieved. The trust in one's own capabilities that the desired goal will be achieved will lead to desired outcomes. Optimistic people have more confident that they will achieve the desired outcome as compared to pessimistic individual (Carver, 2001). 
After an analysis of the theoretical frameworks on these constructs, it is important to explore the literature on this area.

\section{LITERATURE REVIEW}

To my knowledge there are few researches done on fear of negative evaluation, loneliness and life orientation and relation was seen with social connectedness, depression, wellbeing, mental health, life satisfaction among never married men and women, adults and peoples of different localities with these variables. To the best of my knowledge there is no literature found that directly taps fear of negative evaluation, loneliness and life orientation of never married men and women.

The review of literature on this topic has been performed in a chronological manner. The studies documenting the relationship among fear of negative evaluation, loneliness and life orientation are extensive. The literature spans across many decades. It is important to gain an understanding of the literature starting from the 1990s in order to gain deeper insights into the phenomena being explored.

Sernat (1980) proposed that one more factor that contributes to loneliness is the reluctance of individual to enter into interpersonal situations in which he perceives high risk of being embarrassed, rejected, or disappointed. Individuals who fear to be negatively evaluated by others are less likely to disclose their personal or distressful information.

Leary (1990) studied the relationship among loneliness and life orientation. The sample size for the study was 350 adults from different localities and regions. The results had shown that loneliness leads to negative mental health consequences. Also, such individuals tend to have a negative or pessimistic orientation towards life in general. The reactions to social exclusion and loneliness include: isolation, anxiety, jealousy and low self-esteem. Also, there is a negative and predictive association among these factors in relation to the areas being explored.

Costanzo (1992) had studied external socialization and how it is beneficial in terms of the development of social connectedness and as a protective mechanism against loneliness. In addition, the researcher had established that socialization that is achieved developmentally is advantageous in terms of increasing the level of adaptive individuation. It was found that individuals who score high on loneliness tend to have a negative approach towards life in general. Also, their attribution styles are primarily external and negative. The findings had shown that socialization and social connectedness can be seen as protective factors for an individual for combating the different situations in life including the negative experiences associated with never getting married. The availability of such forms of support during the later segments of life can result in positive mental health consequences.

Raja, McGee and Stanton (1992) explored how parent-child attachment styles and interactions during early childhood shape their approach towards social relations. Also, the relationship between social connectedness, loneliness and psychological wellbeing was studied. The sample size was 435 and included adults from different localities of the state of Michigan. The findings showed that social connectedness is learned and that it is positively associated with psychological wellbeing. However, as the study was quantitative and descriptive in nature, the findings cannot be seen as expressing causality. Social connectedness has been identified as a causal factor behind wellbeing in a number of studies but there is also evidence to show that it is rather an outcome of other mental states.

McNair (1992) had studied a sample of African American adult women in therapy. The women in question were seeking therapeutic interventions for overcoming depression and other psychological problems associated with never getting married. One common factor identified in these women are the lack of social connectedness. Semi-structured interviews were conducted with the participants. The findings had shown that social connectedness is itself an independent psychological and social state that contributes towards worsening of the effects of depression, loneliness and isolation and other mental health problems. The provision of therapies centred on increasing the social support and connectedness of adults can lead to better mental health consequences. Also, social connectedness provides the desired levels of support and guidance needed for facing the negative situations in life. In addition, the study had shown that interpersonal support and social connectedness contribute towards minimizing the effects of isolation and hopeless, two cores after effects of major depression.

Resnick, Harris and Blum (1993) studied the relationship among social connectedness, isolation and psychological wellbeing for young adults. The sample included 400 university students. The findings had shown that social connectedness positively predicts psychological wellbeing and has a negative impact on isolation. It has been found that psychological wellbeing is a major contributing factor with life satisfaction. The study in question showed a wide range of positive mental health effects of social connectedness on young adults. The researchers also explored how social connectedness results in improvements in wellbeing and limit isolation. It was found that social connectedness is a means for bonding with people and for perspective taking. It is by identifying with a group and with other people that an individual is able to find the support and association needed for dealing with different mental health problems.

Gaudin and his colleagues (1993) studied a sample of neglectful families. The main aim of the study was to 
investigate the relationship among depression, loneliness and life orientation in these families. The results showed that social connectedness helps in overcoming the mental consequences for individuals belonging to neglectful families. It was also found that there is a negative association between depression and social connectedness. More specifically, it was seen that individuals who scored high on social connectedness reported lower scores on hopelessness. However, the study did not find any gender differences in the sample. Both males and females from neglectful families reported similar levels of hopelessness. The researchers also stated that it is unclear whether social connectedness is a causal factor behind depression or vice versa. This raises the need of exploring predictive and causal relations between social connectedness and mental health conditions.

Badoux and Mendelsohn (1994) had studied the relationship between social connectedness, loneliness and psychological wellbeing. The study was comparative in nature as it conducted a comparative analysis of American and French adults. Also, gender differences were studied in the investigation. The findings had shown that social connectedness scores of married individuals were higher in comparison to unmarried individuals. The study has shown that social connectedness and need to attach oneself to a partner and getting married are culturally learned and that civilizations and societies that promote collectivist living and thinking contribute towards the promotion of mental and physical wellbeing of its members.

Resnick, Harris and Blum (1993) studied the relationship among loneliness, life satisfaction and psychological wellbeing for young adults. The sample included 400 university students. The findings had shown that higher levels of social connectedness and lower levels of loneliness positively predict psychological wellbeing and has a negative impact on isolation. It has been found that psychological wellbeing is a major contributing factor with life satisfaction. The study in question showed a wide range of positive mental health effects of social connectedness on young adults. The researchers also explored how social connectedness results in improvements in wellbeing and limit isolation. It was found that social connectedness is a means for bonding with people and for perspective taking. It is by identifying with a group and with other people that an individual is able to find the support and association needed for dealing with different mental health problems.

Johnston and Eklund (1994) had conducted an investigation to determine the level of life adjustment among never married individuals. It was found that a majority of the individuals scored low on self-esteem, life satisfaction and wellbeing. Also, they scored high on loneliness. It was also found that the level of life adjustment was better for individuals who were married. However, it should be noted that there were a number of unmarried individuals as well who scored high on life satisfaction, wellbeing and has a more positive outlook and life orientation. This is an indication that these areas need to be explored in a detailed manner keeping in view the changing social and cultural dynamics of the modern times in which never getting married is viewed in less stereotypical terms in comparison to the 1990 s.

Frazier and his colleagues (1996) had studied the association between desire for marriage and life satisfaction among never married individuals. The sample included 217 unmarried individuals and 2000 married individuals who had been surveyed and all of them were heterosexual. The findings showed that unmarried individuals attribute the experiences of being single to barriers as well as choices. It was also found that women desire marriage more than men. It was also found that unmarried individuals scored low on social support, life satisfaction and wellbeing. In comparison, married individuals scored high on these constructs which is an indication that married individuals have better orientations towards life and a higher level of life satisfaction.

Andersson (1996) had conducted a study exploring the development of life orientation among never married individuals. The research was based on the use of a meta-analytical approach. The studies reviewed had been pivotal in terms of the provision of a large sample size and an extensive amount of data. The findings showed that life orientation is positive for those individuals who are married in comparison to those who are unmarried. However, the negative life orientation seen among non-married individuals can be accounted for and explained by a wide range of factors. Other factors need to be accounted for in terms of explaining the development of a positive life orientation approach.

Lewi and Moon (1997) studied the advantages and disadvantages of singlehood. It is found that single women have unresolved ambivalence about being single. Women in their study recognized both advantages and disadvantages to singlehood, yet retained a guarded attitude about the possibility of marriage, and although mostly content with being single, many women simultaneously experienced feelings of "loss and grief" about not being married or having children.

Jackson, Soderling and Weiss (2000) had studied the role of specific personality traits among unmarried individuals and how these traits contribute towards the development of their feelings of loneliness. The sample included 317 students. The findings showed that personality traits such as introversion, insecure attachment traits and other related factors accounted for the development of loneliness among never married individuals. The researchers also stated that loneliness also leads to the development of an overall negative orientation towards different aspects of life.

Vincke and Van Heeringen (2002) used a sample of Lesbian and Gay couples in order to document their social connectedness, interpersonal support and loneliness. The sample included 82 Lesbian and Gay couples. The 
findings showed that the provision of low social connectedness and higher levels of interpersonal support predicted their level of loneliness. As these individuals are stereotyped and subject to mistreatment at a large scale even in some developed regions, they have to endure a wide range of social and psychological consequences. Also, in case of interpersonal support, hopeless was seen in a large number of couples. This shows that interpersonal support has a secondary role to play in terms of determining hopelessness in adults. The data on such couples is growing. Many countries and regions have passed laws legalizing such relations. However, it is still unclear whether getting married and interpersonal support can create better mental health prospects for these individuals.

Sandfield and Percy (2003) have examined whether single life negatively influenced single women. In study, single women were found to have an incomplete identity, often feeling lonely and isolated and out of touch with the traditional married family with children. In their study, single women reported that being single was the consequence of their failure to maintain heterosexual relationships, and/or they thought they were at fault in some way for ending past relationships that might have led to marriage. (Sandfield, Percy, 2003)

Moller and his colleagues (2003) had studied young adults and the role of interpersonal and social support in helping them overcome the experiences associated with breakups. Social connectedness measure was used for determining the level of social support. The results showed that social connectedness positively impacts many coping mechanisms used for dealing with such experiences. The availability of individuals to connect with provides an effective means for coping for such individuals. In addition, it was found that social connectedness is a protective mechanism against such experiences. It also contributes towards protecting the individual from other negative conditions in life.

Vanderhorst and McLaren (2005) studied how loneliness predicts depression and level of suicidal ideation in older adults. A community sample of 110 older adults was assessed using the social support scale and loneliness scale. The results showed that few social and interpersonal support and services were linked with higher levels of depression and loneliness as well as higher levels of suicidal ideation. It is an indication that getting married provides the social and cognitive resources needed for dealing with depression, suicidal ideation and other adverse consequences.

Hill (2006) used a sample of American Indians for assessing their level of wellbeing, loneliness and the impact on mental health. It has been found that for Indians moving to America and trying to integrate themselves into a new culture was a major challenge. Initially, they did face a number of problems in making adjustment to the new culture. It was also observed that cultural shock is a negative mechanism that impacts the mental health of individuals. However, the degree of social connectedness they develop with time allows them to combat with the cultural chock and other negative experiences associated with moving to a new culture.

Choi (2009) used a sample of 174 depressive unmarried patients to study the impact of social never getting married on depressive symptomatology. The purpose of the study was to assess the relationship between loneliness and life orientation. The sample included members of low income groups. The findings showed that higher levels of loneliness lead to the development of a negative orientation towards life. It was also found that these individuals had high fears of being evaluated or being viewed in negativistic terms.

Cacioppo, Fowler, and Christakis (2009) studied the structure and diffusion of loneliness in social connections. Results suggested that loneliness is not just taken as an individual experience but it is also a function of group. Individual experiencing the feelings of loneliness tend to accompanying the persons who are lonely. It was found that loneliness spread more quickly and strongly than perceived social connections. This affect is stronger for geographically close as compare to distant friends and is greater for women as compare to men. Even this effect can also extend up to three levels of separation in the social connections. It transmits via a contagious process.

Margalit (2010) researched that loneliness is a major source of distress among never married individuals. It is seen a noteworthy developmental problem that can negatively influence the short and long term relations of individuals. In this regard, the researchers had also found the role of childhood experiences and other related factors in terms of the development of loneliness. It was found that though these mediums provide an effective means for wellbeing and a means for overcoming isolation, it did not contribute towards reducing the level of loneliness.

Smithson (2011) explored the relationship between fear of negative evaluation, interpersonal support, meaning in life and psychological wellbeing. The midlife crisis faced by adult women who were never married were assessed in the study. The data collection was done from a major metropolitan city. The results showed that fear of negative evaluation, loneliness and wellness scores were higher for women who were educated and belonging to middle- and high-income groups. For women with low income groups, level of social connectedness did not contribute much towards their tendency to deal with the problems associated with depression and other psychological problems. However, it was found that there is some connection between social connectedness and how efficiently these women were able to deal with their midlife crisis especially when they are unmarried. The study provided implications for the provision of counselling services for women facing midlife crisis.

Literature showed that loneliness is the product of ancient times. As Mijiskovic (2012) explored it in his 
research conducted on loneliness and personal identity. Results criticized those who suggest that loneliness is a product of modern society. He explained that everywhere man has always suffered this acute loneliness.

Şar et al. (2012) studied the role of internet in helping individuals in overcoming loneliness and hopelessness. The researchers had hypothesized that the internet served as a means for social connectedness for these individuals. It also provided them with the level of interpersonal support they needed for dealing with their psychological issues. The sample for the study included 154 elderly individuals. Results showed that social media websites and other internet links helped them in interacting with people with whom they can identify with. These websites provided them a source of social connectedness and helped them in overcoming their loneliness and other problems. The presence of a number of important and friendly individuals in their lives helped them in dealing with the crisis of later life. Another important finding to consider is that social connectedness is an effective measure for providing opportunities and means for coping. The lack of such sources limits the chances of recovery for these individuals. Another important aspect to consider is that the internet provides social support for these individuals but the levels of communication and the quality of relations they have are comparatively limited in comparison to their face to face relations. This finding shows that social connectedness based on face to face communication and relationship dynamics is more facilitative and positive for dealing with mental health problems.

Steptoe and his colleagues (2013) studied the relationship of loneliness, social isolation and all-cause mortality in both male and female adults. Results revealed a significant of loneliness and social isolation with increased mortality. Nevertheless, both loneliness and social isolation were found to impair wellbeing and quality of life.

Tatlilioglu (2013) studied the importance of providing cognitive behaviour psycho-education to never married adults experiencing problems of social isolation and loneliness. A randomized control trial was conducted for studying the impact of the online counselling intervention in improving the feelings of loneliness, isolation and level of social connectedness. The sample included 129 individuals who were subject to the treatment. The control group included 100 individuals. The participants in the experimental group had been matched in terms of their level of depression, stress, social support and other related data. The results showed that the provision of online counselling services helped them in overcoming their loneliness, hopeless and other related problems. They were also able to report a reduction in their depression scores after the provision of counselling. The study established a causal connection between online counselling for psycho education of the adults about loneliness, depression and other related problems often seen in the lives of never married adults living in western and some eastern cultures. However, this does not mean that online counselling is an equally effective replacement for face to face counselling.

Chen and Feeley (2015) explored the relationship among interpersonal support, social strain, loneliness and wellbeing in never married older adults. The participants included belonged to retirement and old homes. The sample size was 7637 individuals aged 50 years and older. The findings showed that support from partner, friends and family helped in alleviating the level of loneliness. The lack of interpersonal support contributed towards increasing loneliness. It was also found that social strain and lack of social support contributed towards the development of psychological problems for these individuals. Social strain was found as having direct and indirect effects on loneliness and isolation. Individuals who had sufficient levels of interpersonal support reported more hopefulness about their remaining segments of life. In addition, interpersonal support positively predicted the level of wellbeing in these individuals.

Chi and his colleagues (2016) studied the mediating role of belongingness in terms of the relationship between fear of negative evaluation and depression among never married individuals. The findings showed that never married individuals had higher scores on fear of negative evaluation. In other words, they are of the view that despite of the change in values and cultural beliefs regarding marriage, still the idea of never getting married is viewed negatively across a wide range of cultures. In addition, it was found that the level of belongingness among individuals mediates the relationship between fear of negative evaluation and depression. It was also found that never getting married is linked with higher levels of depression.

Beller and Wagner (2017) studied the differential effects of living alone, quality of social networking, size of the social connections and their impact on physical, mental and cognitive health. Data was collected from 767 adults living alone. Data collection was done using a specialized questionnaire for measuring their social connectedness, social network size, intensity and level of interactions etc. The findings showed that social connectedness contributed towards reduced loneliness. Also, it was seen that adults who lived in isolation and had a limited social network had more psychological and physical health problems. The cognitive health of individuals who were more socially connected differed from adults who lived alone and experienced loneliness. The findings suggest that social support should be aimed at increasing the size and quality of social networking for older adults keeping in view the positive mental and physical benefits of social connectedness.

\section{Aims and Objectives}


The aims and objective of my research study are given below:

i. To investigate the relationship of fear of negative evaluation, loneliness and life orientation among never married men and women.

ii. To contribute towards a better understanding of the development of loneliness, life orientation and fear of negative evaluation among individuals who are never married

iii. To identify the positive and negative effects of never getting married on the psycho-social functioning of never married men and women

iv. To explore the gender differences in terms of loneliness, fear of negative evaluation and life orientation among never married men and women.

\section{Hypotheses}

The hypotheses of the study are as follows:

i. There would be a significant relationship among fear of negative evaluation, loneliness and life orientation among never married men and women

ii. Loneliness and fear of negative evaluation would predict life orientation among never married men and women

iii. There would be significant gender differences among participants in terms of fear of negative evaluation, loneliness and life orientation among never married men and women

iv. Loneliness would mediate the relationship between fear of negative evaluation and life orientation among never married men and women.

\section{Problem Statement}

Studies on this area had started in the 1970s and 1980s. There is no work conducted in this area in Pakistan. The current study is therefore designed to investigate that how the fear of negative evaluation mediate the life orientation of never married persons and how it play role on psychological functioning. A number of researchers were interested in terms of assessing the differences in the psychological strengths and traits of individuals who are married in comparison to those who are unmarried. Also, research has been done to explore the psycho-social determinants of the phenomenon of remaining single. It is well known among older and younger people that the presence of a spouse is termed an important source of emotional and physical wellbeing. Some researchers argue that the beneficial effects are mainly seen due to the social integration function played by marriage.

However, most recently, interest in this area has re-emerged primarily due to the need of conducting comparative assessments among never married individuals and to investigate their meaning and purpose in life and their experience of loneliness. It has been found that the presence of an individual facilitates one's level of social interaction and is important for the purpose of building companionate relations. Other important functions of getting married include: protection, security, reproduction, social support, sharing one's burden, having a meaning and purpose in life, going beyond the needs of the self, leaving behind one's progeny and a lot more. However, there is a gap in literature on this area in Pakistan that needs to be studied. Also, the social and cultural dynamics of Pakistan are quite different from the western world and the idea of getting married is central to the culture. The present study targeted this gap in literature and focused on providing more detailed insights about never getting married.

\section{Rational of the Study}

The treatment with never married people in Pakistan is not a hidden story. People use to stalk even for little things for which they can insult, humiliate and stigmatize men and women especially when they know that they are single. It is critical to note that despite of the appeal of remaining single and leading a life free from certain responsibilities, there are a number of negative sides to not being married. It is therefore, essential to explore the emotional problems experience by them and extend of risk factors which are troublesome of never married men and women's mental health and create obstacle in future progress.

To best of my knowledge there is no work conducted in Pakistan on this topic. This study is hence designed to investigate the extend of fear of being negatively evaluated by other, how it effects their life, where the story ends up i.e. on loneliness or in the main stream and where their life orientation stands i.e. optimism or pessimism among men and women who are not married for any reason.

\section{Significance of the Study}

Never married men and women have to face various challenges in our society even when they are functioning well and contributing in different fields. Our society raises many challenges for those who are somehow gone through different kind of crisis and challenges in life after which they are left alone and isolated in this society where marital status matters a lot.

This study will contribute to highlight this dilemma so that we can do something for this issue in future to 
prevent such persons from psychological pain. The study will be beneficial in the terms that it will enable the society to understand that never married men and women are not an emblem of bad person. If never married men or women are single, never married, it doesn't mean that they have faults in them. The study will help in understanding that married or unmarried is just a status and nothing more than that. So never married men or women should not be judged by their status but by their work and contribution towards the society.

\section{Hypothesized Mediation Model}

The hypothesized mediation model among three variables fear of negative evaluation, loneliness and life orientation is given below:

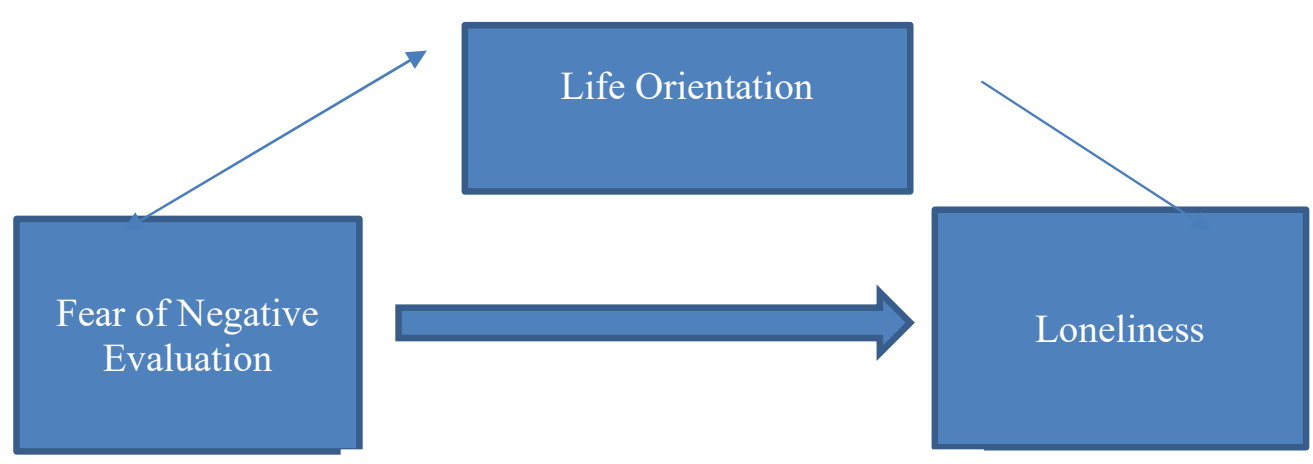

Fig:2 Hypothesized Mediation Model

\section{III.METHOD AND MATERIAL}

\section{Research Design}

Correlation research design was used. This design was employed for the purpose of assessing the relationship among fear of negative evaluation, loneliness and life orientation among never women. The purpose of the study was also to find out the relationship among three variables.

\section{Sample}

The study was conducted during 2017 academic year. The sample size of the study was 200 with 100 males and 100 females. Purposive sampling technique was used. The age range of the sample was from 30 to 50 years $(M=33$, $S D=6.66)$.

\section{Sampling Strategy}

Purposive sampling was used for study of this research.

\section{Inclusion Criteria}

The criterion for inclusion was based on including those men and women who were never married and who were beyond their $30 \mathrm{~s}$.

\section{Exclusion Criteria}

Males and those women who were within their 30s.

\section{Measuring Instruments}

The measuring instruments that are used in this study are Fear of Negative Evaluation Test (FNE), Revised UCLA Loneliness Scale (R-UCLA) and Life Orientation Test Revised (LOT-R). There description is given below.

\section{Fear of Negative Evaluation}

The Fear of Negative Evaluation (FNE) test was developed by Watson and Friend in 1969. This test contains 30 items that are responded through true and false format. The time span to complete this test is 10 minutes. The scores of the scale range from 0 to 30 . Individuals scoring from 0 to 12 are classified as low on FNE, 13 to 20 are moderate and 21 to 30 are those who are in the high range. The scale has been demonstrated as having a high internal consistency reliability. The Cronbach alpha of the scale is .97. In terms of its validity, the scale does not correlate strongly with varying measures of social apprehension including SAD PERSONS SCALE. The items of the scale include e...I rarely worry about what kind of impression I am making on someone. I am afraid that people will find fault in me. 


\section{Revised UCLA Loneliness Scale}

Revised UCLA Loneliness Scale was developed by Dr. Russell in 1996. This is a 20 item measure used for the purpose of assessing subjective feelings of loneliness as well as the variable feelings linked with social isolation. The participants are required to rate each item on a scale of 1 (never) to 4 (often). The scale is a revised version of the original UCLA scale. The revision was done for the purpose of simplifying the wording used. The scale has been demonstrated as having a high internal consistency reliability of .77. The items include e.g. 1. I feel in tune with the people around me. There are people I can talk to.

\section{Life Orientation Test Revised (LOT-R)}

Life Orientation Test Revised (LOT-R) was developed by Scheier in 1994. This test is a 10 item measure for the purpose of assessing optimism and pessimism. Of the 10 items, 3 are used for measurement of pessimism, 4 are used as fillers and 3 for optimism. The respondents are asked to respond on a 4 point scale $0=$ strongly agree till $0=$ strongly disagree. The scale has been demonstrated as having a good internal consistency reliability .83 .

\section{Data Analysis}

Data analysis was done by using SPSS 21. Correlation, regression, independent sample $t$ - test, ANOVA and mediation analysis was used.

i. Descriptive statistics were calculated for sample distribution.

ii. Pearson correlation coefficient was used to investigate the relationship among study variable.

iii. Regression analysis was used to determine for prediction of optimism and pessimism with loneliness and fear of negative evaluation.

iv. ANOVA and mediation analysis were used to determine the effect of independent variables on dependent variables.

\section{Procedure}

Permission was taken from the administration of the university. Administration issued the permission letter. Data collection was done by contacting participants at their respective workplaces and at their homes. The sample was searched for through the personal links and through snowball technique as it allowed for tracing out men and women who had never married.

\section{Ethical Consideration}

Following ethical consideration was kept in mind during conducting the research.

i. Scales were used after the permission of the concerned authorities through E-mail. A copy of E-mail is attached in appendix as well.

ii. A permission letter which explained the nature and purpose of the research was also issued by the university authorities.

iii. $\quad$ Purpose of the study was also defined to the participants.

iv. Written consent form was also taken from the participants.

v. They were given the right to withdraw or decline from the research whenever they want.

vi. It was assured that their information would keep confidential and would be used for research purpose only.

\section{IV.RESULTS}

The section of the result consists of descriptive statistics and inferential analysis. The descriptive statistics, the demographics variables are discussed by calculating frequencies and percentages. The inferential analysis was done by using SPSS 21. Correlation, regression, independent sample t test, ANOVA and mediation analysis were used.

Correlational analysis is run between fear of negative evaluation, loneliness and life orientation optimism and pessimism to investigate the relationship between them. Multiple regression analysis was used for prediction of optimism and pessimism with loneliness and fear of negative evaluation. Mediation analysis was used to see mediating effect of loneliness on the association between fear of negative evaluation and optimism. Independent sample t test and mediation analysis were used.

\section{Descriptive Statistics}

The section of descriptive statistics describes the demographics characteristics of the sample which consist of gender, age socioeconomic status of family system. 
Table 1

Frequency Statistics of Demographic Variables of the Sample $(N=200)$

\begin{tabular}{lll}
\hline Variables & $F$ & $\%$ \\
\hline Gender & 100 & 50 \\
Male & 100 & 50 \\
Female & & \\
Age & 97 & 49.5 \\
30 to 40 & 103 & 51.5 \\
40 to 50 & 200 & 100 \\
Total & \\
\hline
\end{tabular}

The table indicates that $50 \%$ of the participants were male and $50 \%$ were females. It was also found that in terms of age range, $49.5 \%$ participants belonged to the age range of 30 to 40 while 51.5 belonged to the age range of 40 to 50 .

Table 2

Frequency Statistics of Demographic Variables of the Sample $(N=200)$

\begin{tabular}{lll}
\hline Variables & $F$ & $\%$ \\
\hline Socioeconomic Status & & \\
Lower & 4 & 2 \\
Middle & 185 & 92.5 \\
Upper & 11 & 5.5 \\
Family System & & 36 \\
Joint & 72 & 64 \\
Nuclear & 128 & 100 \\
Total & 200 & \\
\hline
\end{tabular}

In terms of SES, about $2 \%$ of the participants belonged to low SES, $92.5 \%$ belonged to Middle SES while $5.5 \%$ belonged to higher SES. In terms of family systems, $36 \%$ belonged to joint and $64 \%$ belonged to nuclear family systems.

\section{Inferential Analysis}

The inferential analysis was done by using SPSS 21. Correlation, regression, independent sample t test, ANOVA and mediation analysis were used. Correlational analysis is run between fear of negative evaluation, loneliness and life orientation optimism and pessimism to investigate the relationship between them. Multiple regression analysis was used for prediction of optimism and pessimism with loneliness and fear of negative evaluation. Mediation analysis was used to see mediating effect of loneliness on the association between fear of negative evaluation and optimism. Independent sample t test and mediation analysis were used.

\section{Hypothesis Testing}

The purpose of the study was to investigate the relationship between fear of negative evaluation, loneliness and life orientation among never married men and women.

Table 3

Correlation among Fear of negative evaluation, loneliness, life orientation optimism and pessimism $(N=200)$

\begin{tabular}{|c|c|c|c|c|}
\hline Variable & $F N E$ & $R-U C L A$ & $\begin{array}{l}\text { LOT-R } \\
\text { Optimism }\end{array}$ & $\begin{array}{c}\text { LOT-R } \\
\text { Pessimism }\end{array}$ \\
\hline 1. FNE & - & $.47 * *$ & $-.29 * *$ & .07 \\
\hline 2. R-UCLA & & - & $-.49 * *$ & $.23 * *$ \\
\hline 3.LOT-R & & & & \\
\hline $\begin{array}{l}\text { Optimism } \\
\text { Pessimism }\end{array}$ & & & - & .02 \\
\hline
\end{tabular}

Note. Fear of Negative Evaluation (FNE), Revised UCLA Loneliness scale(R-UCLA), Life Orientation Test Revised (LOT-R) $* * p<.01$

Pearson Product Moment Correlation was run to find out the relationship among fear of negative evaluation, loneliness, life orientation optimism and pessimism. The results indicated that there was a significant positive relationship between fear of negative evaluation and loneliness $(r=.47, p<.01)$ and a significant negative relationship between fear of negative evaluation and optimism $(r=-.29, p<.01)$. Also, there was a significant positive relationship between loneliness and pessimism $(r=-23, p<.01)$. 
Table 4

Mean Differences on Fear of Negative Evaluation, Loneliness, Life Orientation Optimism and Life Orientation Pessimism $(N=200)$

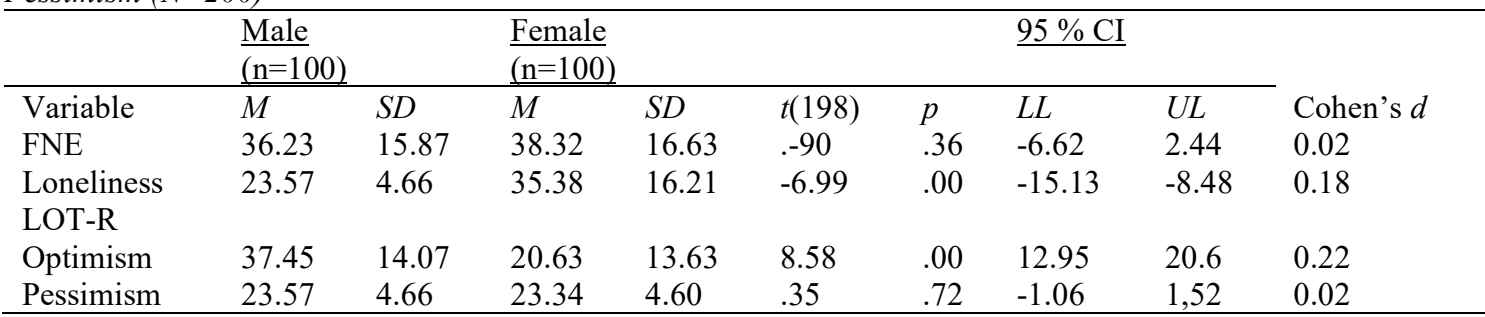

Note. $C I=$ confidence interval, $\mathrm{M}=$ mean, $\mathrm{SD}=$ standard deviation, $\mathrm{LL}=$ lower limit, $p=$ significant value, $U L=$ upper limit. FNE=Fear of Negative Evaluation

Table 4 shows mean differences between male and females on Fear of Negative Evaluation, Loneliness, Life Orientation Optimism and Pessimism. The results showed that there are significant mean differences among participants on loneliness $(t=-6.99, p<.05)$ and optimism $(t=8.58, p<.05)$. However, there were no significant differences among participants on pessimism and fear of negative evaluation. In relevance to loneliness, females $(M=35.38, S D=16.21)$ scored higher in comparison to males $(M=23.57, S D=4.66)$. In relevance to optimism, males scored higher $(M=37.45, S D=14.07)$ in comparison to females $(M=20.63, S D=13.63)$.

Table 5

Fear of Negative Evaluation and Loneliness as Predictors of Optimism $(N=200)$

\begin{tabular}{lllll}
\hline Variable & $B$ & $S E$ & $B$ & $95 \% C I$ \\
\hline Constant & 48.43 & 2.74 & & {$[43.01,53.84]$} \\
FNE & -.07 & .07 & -.08 & {$[-.21, .05]$} \\
Loneliness & $-.56^{*}$ & .08 & -.46 & {$[-.73,-.39]$} \\
$r^{2}$ & & & .25 & \\
$F$ & & & 33.57 & \\
$R$ & & & .50 & \\
\hline$* p<.05, \mathrm{CI}=$ Confidence Interval & & &
\end{tabular}

Multiple regression analysis was used for prediction of optimism. It was found loneliness $(\beta=.-.56, p<.05)$ significantly and negatively predicted optimism. At the same time, fear of negative evaluation did not significantly predict optimism. $r^{2}$ indicates that $25 \%$ variance in optimism.

Table 6

Fear of Negative Evaluation and Loneliness as Predictors of Pessimism $(N=200)$

\begin{tabular}{|c|c|c|c|c|}
\hline Variable & $B$ & $S E$ & $B$ & $95 \% C I$ \\
\hline Constant & 21.28 & .88 & & {$[19.45,23.02]$} \\
\hline FNE & -.01 & .02 & -.04 & {$[-.05, .03]$} \\
\hline Loneliness & $-.09 *$ & .02 & .25 & {$[.03, .14]$} \\
\hline$r^{2}$ & & & .05 & \\
\hline$F$ & & & 5.89 & \\
\hline$R$ & & & .23 & \\
\hline
\end{tabular}


Table 7

Mediating Effect of loneliness on the Association between fear of negative evaluation and optimism $(N=200)$

\begin{tabular}{llll}
\hline Measures & $B$ & $S E$ & $P$ \\
\hline Step 1 (Path c) & & & .000 \\
Outcome: Optimism & -.38 & .05 & \\
FEN & & & .000 \\
$\begin{array}{l}\text { Step 2 (Path a) } \\
\text { Outcome: Loneli }\end{array}$ & -.07 & .06 & \\
FNE & & & .000 \\
$\begin{array}{l}\text { Step 3 (Path b) } \\
\text { Outcome: Optimism }\end{array}$ & -.56 & .08 & \\
$\begin{array}{l}\text { Loneliness } \\
\text { (Path c') }\end{array}$ & & & .255 \\
Mediator: Loneliness & & .06 & \\
Predictor: FNE & -.07 & &
\end{tabular}

Note. FNE=Fear of Negative Evaluation, Loneli=Loneliness, Optimism, $\beta=$ standardized coefficient. ${ }^{*} p<.05$, $* * p<.01$

In terms of the current investigation, Preacher and Hayes (2008) bootstrapping method was used for the purpose of testing and observing whether loneliness mediated the association between fear of negative evaluation and optimism.

The core assumption of mediation analysis is to assess whether a significant relationship is seen between the predictor and the outcome variable. Correlation Matrix (See table of correlations) had shown that all variables being researched were significantly associated.

Path $\mathrm{c}$ in the table shows the predictive association between fear of negative evaluation as the independent variable and optimism as the dependent variable without controlling for loneliness as the mediator. There was a significant predictive relationship between fear of negative evaluation as the independent variable and optimism as the dependent variable without controlling the effects of loneliness $(\beta=-.38, p<.01)$.

Path a shows relationship between fear of negative evaluation as the predictor variable and loneliness as the dependent variable. This path has shown that fear of negative evaluation was significantly associated with the mediator variable loneliness $(\beta=-.07, p<.01)$.

Path $\mathrm{b}$ in the table shows loneliness as the independent variable and life orientation optimism as the dependent variable. There was a significant predictive relationship that was seen $(\beta=-.56, p<.05)$.

The path c' (c prime path) shows the association between fear of negative evaluation as the independent variable and life orientation optimism as the dependent variable when controlling for the mediator (loneliness). If fear of negative evaluation has no effect on life orientation optimism and c' model is no more significant, then it can be said that there is complete mediation. This is true for this case as the path c' becomes insignificant in the final step $(\beta=-.07, p=\mathrm{ns})$ which is evidence for complete mediation.

\section{DISCUSSION AND CONCLUSION}

The purpose of the study was to conduct an assessment on the relationship among fear of negative evaluation, loneliness and life orientation among never married women and men. The results showed that the variables are in fact related to one another.

First, it was hypothesized that there would be a significant relationship among fear of negative evaluation, loneliness and life orientation. The results offered a confirmation of this hypothesis. The results indicated that there was a significant positive relationship between fear of negative evaluation and loneliness and a significant negative relationship between fear of negative evaluation and life orientation optimism.

A number of studies in the past literature have offered a confirmation of this hypothesis. Studies have shown that for never married men and women score high on loneliness and also have problems in relevance to the fear of negative evaluation. This fear is higher in women in comparison to men. The same holds true for loneliness which is more prevalent in women in comparison to men. Leary (1990) studied the relationship among loneliness and life orientation. The sample size for the study was 350 adults from different localities and regions. The results had shown that loneliness leads to negative mental health consequences.

Costanzo (1992) had studied external socialization and how it is beneficial in terms of the development of social connectedness and as a protective mechanism against loneliness. In addition, the researcher had established that socialization that is achieved developmentally is advantageous in terms of increasing the level of adaptive individuation. It was found that individuals who score high on loneliness tend to have a negative approach towards life in general. Also, their attribution styles are primarily external and negative. The findings had shown that socialization and social connectedness can be seen as protective factors for an individual for combating the 
different situations in life including the negative experiences associated with never getting married. The availability of such forms of support during the later segments of life can result in positive mental health consequences.

Secondly, it was hypothesized that loneliness and fear of negative evaluation would predict life orientation among never married individuals. The results partially confirmed the hypothesis. It was found that loneliness significantly predicted pessimistic life orientation. However, fear of negative evaluation did not significantly predict life orientation. These findings are supported in the literature on this area. It has been established that never married individuals experience loneliness as a result of which they are inclined towards showing a negative orientation towards life. Other studies have found that there is a strong predictive association between loneliness and pessimistic life orientation. It is critical to note that pessimistic life orientation is the consequence of experiencing extensive levels of loneliness. However, there are some studies that have provided a disconfirmation of this hypothesis. It is on this basis that it can be said that there are mixed findings on this area.

Thirdly, it was hypothesized that there would be significant gender differences among never married men and women on fear of negative evaluation, loneliness and life orientation. The results of the present study showed that there are significant gender differences among participants but only for loneliness and optimistic life orientation. It was found that never married females scored higher on loneliness in comparison to males. Another finding was that never married males scored high on optimistic life orientation in comparison to females. Studies have offered a confirmation of the findings of the present study. The literature has shown that never married women and men do tend to differ across the various dimensions including psychological wellbeing, life satisfaction, self-esteem, loneliness, hopeless etc. The variations among the scores can be explained to the social, cultural and individual variables. In addition, the attachment styles and other related factors are also important in terms of explaining the differences among never married men and women on loneliness and life orientation. Cacioppo, Fowler, and Christakis (2009) studied the structure and diffusion of loneliness in social connections.

Results suggested that loneliness is not just taken as an individual experience but it is also a function of group. Individual experiencing the feelings of loneliness tend to accompany the persons who are lonely. It was found that loneliness spread more quickly and strongly than perceived social connections. This affect is stronger for geographically close as compare to distant friends and is greater for women as compare to men. Even this effect can also extend up to three levels of separation in the social connections. It transmits via a contagious process.

Fourthly, it was hypothesized that loneliness would mediate the association between fear of negative evaluation and life orientation. The findings of the study confirmed this hypothesis by showing that loneliness completely mediated the relationship between fear of negative evaluation and optimistic life orientation. For pessimistic life orientation as the dependent variables, the mediation was non-significant. Studies have shown that loneliness has a major role to play in terms of impacting life orientation. There are also theories that have explained this mediated relationship. Relational Regulatory Theory of Interpersonal Support is an effective mechanism in this regard.

This theory has been designed to assess the perceived effects of social support and mental health for never married individuals and also for those individuals who have been abandoned by their families. It has been found that perceived social and interpersonal support has direct effects on the mental health of individuals who are never married. The relationship is mediated by individuals who are required to regulate their emotions through ordinary and shared conversations. In order to cope with stress, they should be able to achieve effective regulation of their emotions. In case of non-regulation or lack of regulation, individuals tend to experience negative psychological consequences such as hopelessness, isolation, stress, depression etc. The main mechanism explaining the association is relational in nature.

Andersson (1996) had conducted a study exploring the development of life orientation among never married individuals. The research was based on the use of a meta-analytical approach. The studies reviewed had been pivotal in terms of the provision of a large sample size and an extensive amount of data.

Tatlilioglu (2013) studied the importance of providing cognitive behaviour psycho-education to never married adults experiencing problems of social isolation and loneliness. It was found that loneliness does have a considerable amount of influence on life orientation optimism or negative. It is a fact that the level of loneliness an individual has in his or her life results in an overall change in the overall perception of his or her life.

\section{Limitations}

The limitations of the study are given below.

i. Sample size was limited to 200 and was collected from a diverse population. However, as the sample was limited to a few regions, the external validity of the study can be questioned.

ii. The study has established correlational associations but it does not indicate cause and effect findings. For establishing cause and effect, it is important to use experimental designs

iii. The findings of the study could have been better established through complementing the findings using qualitative measures 
iv. There were some ethical concerns in conducting this study. However, a risk and benefit analysis done by the supervisor and some other teachers had indicated that the benefits outweigh the costs

\section{Implications}

The implications of the study are given below:

i. The study shows that never married individuals need to be provided with counseling and therapeutic services. The provision of such services by social workers, psychologists and other mental health experts across a wide range of settings can result in improvement in the psychological functioning of individuals

ii. There is also a need for developing specialized approaches and counseling measures for bringing in improvements in the living conditions of such individuals

iii. The findings also span to media outlets that need to work on promoting the need to get married and should emphasize awareness about interpersonal relations

iv. Parents also need to be provided with awareness on how the form of attachment they build in their children lead to long term consequences that can be positive or negative depending upon their parenting

v. The study also has implications in social psychology especially in the domain of interpersonal relations. More studies and researches need to be conducted on this area in order to be able to gain insights into how and why never getting married leads to psychological problems and issues

\section{Recommendations}

The recommendation of the study is given below.

i. Qualitative studies should be done on this area in order to gain detailed insights about how and why fear of negative evaluation and loneliness influence life orientation.

\section{Conclusion}

The study has established that fear of negative evaluation is a major determinant of the negative life orientation among individuals. There is a significant positive relationship among loneliness and fear of negative evaluation and a significant negative association between loneliness and life orientation optimism and fear of negative evaluation and life orientation optimism. Also, loneliness predicted positive and negative life orientation. Another finding was that males and females differed significantly on loneliness and life orientation optimism. Another conclusion is that loneliness among individuals has a mediating role to play between the association of fear of negative evaluation and life orientation.

Thus, it can be concluded that never getting married is an overall negative experience and that is the major determinant of loneliness and fear of negative evaluation. It was also found that females have higher level of concerns in relation to fear of negative evaluation in comparison to females. It is due to their singlehood due to which they are fearful of negative evaluation at the hands of the society. The same holds true for men who are fearful of negative evaluation due to their not getting married. There are multiple social and cultural factors that can explain their negative experiences. Apart from this, the study has shown quantitatively how fear of negative evaluation influences and impacts life orientation.

\section{REFERENCES}

Albano, A., \& Hayward, B. (2004). Social anxiety disorder. In T. H. Ollendick (Ed.), Phobic and anxiety disorders in children and adolescent: A clinician (pp. 198-235). NC, USA: Oxford University Press.

Andersson, G. (1996). The benefits of optimism: A meta-analytic review of the Life Orientation Test. Personality and Individual Differences, 21(5), 719-725.

Badoux, A., \& Mendelsohn, G. A. (1994). Subjective well-being in French and American samples: Scale development and comparative data. Quality of Life Research, 3(6), 395-401.

Berg, J. H., \& Paplau, L. A. (1982). Loneliness: The relationship of self-disclosure and androgyny. Personality and Social Psychology Bulletin, 8(4), 624-630. http://dx.doi.org/10.1177/0146167282084004

Buswell, D. (2013). Amazing ageing. London: Mx Publishing.

Cacioppo, J. T., \& Patrick, W. (2008). Loneliness: Human nature and the need for social connection. WW Norton \& Company.

Cacioppo, J. T., Hughes, M. E., Waite, L. C., \& Thisted, R. A. (2006). Loneliness as a specific risk factor for depressive symptoms: Cross-sectional and longitudinal analysis. Psychology and Aging, 21(1), 140-144.

Carver,C. S. (2001). Optimism: definition and history. Retrieved from http://cancercontrol.cancer.gov/brp/constructs/dispositional_optimism/dispositional_optimism.pdf

Chen, Y., \&Feeley, T. H. (2015). Social support, social strain, loneliness, and well-being among older adults An analysis of the Health and Retirement Study. Journal of Social and Personal Relationships, 31(2), 141-161.

Chu, C., Buchman-Schmitt, J. M., Moberg, F. B., \& Joiner, T. E. (2016). Thwarted belongingness mediates the relationship between fear of negative evaluation and depressive symptomatology. Cognitive therapy and 
research, 40(1), 31-37.

Chu, C., Buchman-Schmitt, J. M., Moberg, F. B., \& Joiner, T. E. (2016). Thwarted belongingness mediates the relationship between fear of negative evaluation and suicidal ideation. Cognitive therapy and research, 40(1), 31-37.

Costanzo, P. R. (1992). External socialization and the development of adaptive individuation and social connection. Psychosomatic medicine, 53(6), 598-607.

Crick, N. R., Grotpeter, J. K., \&Rockhill, C. M. (1999). A social information processing approach to children's loneliness. Loneliness in childhood and adolescence, 153-175.

Dean, J. (2011). Pessimism vs Optimism. Retrieved from http://psychcentral.com/blog/archives/2011/03/17/pessimism-vs-optimism/

Dumber, R. I. M. (2004). Gossips in evolutionary perspective. Review of General Psychology, 8, 100-110.

Flader, D., Grodzicki, W. \& Schroter, K. (1982). Psychoanalyze als Gesprach. Intraktionsanalytische Untre Therapie and Supervision. Frankfurt/Main: Suhrkamp.

Frazier, P., Arikian, N., Benson, S., Losoff, A., \& Maurer, S. (1996). Desire for marriage and life satisfaction among unmarried heterosexual adults. Journal of Social and Personal Relationships, 13(2), 225-239.

Frazier, P., Arikian, N., Benson, S., Losoff, A., \& Maurer, S. (1996). Desire for marriage and life satisfaction among unmarried heterosexual adults. Journal of Social and Personal Relationships, 13(2), 225-239.

GaudinJr, J. M., Polansky, N. A., Kilpatrick, A. C., \&Shilton, P. (1993). Loneliness, depression, stress, and social supports in neglectful families. American Journal of Orthopsychiatry, 63(4), 597.

Hawkley, L. C., \& Cacioppo, J. T. (2010). Loneliness matters: a theoretical and empirical review of consequences and mechanisms. Annals of Behavioral Medicine, 40(2), 218-227.

Hill, D. L. (2006). Sense of belonging as connectedness, American Indian worldview, and mental health. Archives of Psychiatric Nursing, 20(5), 210-216.

House, A. \& Stark, D. (2002). Anxiety in medical patients. Brit Med Journal, 325, 207-209. DOI:http//doi.org/10.1136/bmj.325.7357.207.

Jackson, T., Soderlind, A., \& Weiss, K. E. (2000). Personality traits and quality of relationships as predictors of future loneliness among American college students. Social Behavior and Personality: an international journal, 28(5), 463-470.

Johnston, M. W., \&Eklund, S. J. (1994). Life-Adjustment of the Never-Married: A Review with Implications for Counseling. Journal of Counseling \& Development, 63(4), 230-236.

Karabulut, E. O., Bahadir, Z., Cretel, Z., Pulur, A. (2013). Investigation of fear of negative evaluationof young national kicks boxers in terms of some variables. In Ovidius University Annuals, Physical Education and Sport/Science, Movements and Health Series (Vol. 13, No. 2 Suppl., pp183-187). Ovidius University Press.

Khan, A. (2006). Optimism vs. pessimism. Retrieved from http://www.thisisawar.com/HealthOptimism.htm

La Greca, A., \& Lopez, N. (1998). Social anxiety among adolescents: Linkages with peer relations and friendships. Journal of Abnormal Child Psychology, 26, 83-94.

Lakey, B., \& Orehek, E. (2011). Relational regulation theory: a new approach to explain the link between perceived social support and mental health. Psychological review, 118(3), 482.

Leary, M. R. (1990). Responses to social exclusion: Social anxiety, jealousy, loneliness, depression, and low selfesteem. Journal of Social and Clinical Psychology, 9(2), 221-229.

Lewis, Karen G., \& Moon, S. (1997). Always single and single again women: A qualitative study. Journal of Marital and Family Therapy, 23(2), 115-134.

Margalit, M. (2010). Loneliness Conceptualization. In Lonely Children and Adolescents (pp. 1-28). Springer New York.

McNair, L. D. (1992). African American women in therapy: An Afrocentric and feminist synthesis. Women \& therapy, 12(1-2), 5-19.

Miller, R. A. (1995). On the nature of embarrass-ability: Shyness, social evolution, and social skill. Journal of Personality, 63(2), 315-339.

Mijuskovic, B. C. (2012). Loneliness in philosophy, psychology and literature. Bloomington, IN: Universe Books.

Moller, N. P., Fouladi, R. T., McCarthy, C. J., \& Hatch, K. D. (2003). Relationship of attachment and social support to college students' adjustment following a relationship breakup. Journal of Counseling \& Development, 81(3), 354-369.

Monzani, D., Steca, P., \& Greco, A. (2014). Brief report: Assessing dispositional optimism in adolescence-Factor structure and concurrent validity of the Life Orientation Test-Revised. Journal of adolescence, 37(2), $97-$ 101.

Moustakas, C. E. (1961). Loneliness. New York: Prentice-Hall.

Peplau, L. A., \& Perlman, D. (1979, June). Blueprint for a social psychological theory of loneliness. In Love and attraction: An interpersonal conference (pp. 101-110). Pergamon Press New York.

Perlman, D. \& Peplau, L. A. (1982). Perspective on loneliness. In L. A. Peplau \& D. Perlman, Loneliness: A source 
book of current theory, research, and therapy (Vol. 36) (pp. 1-18). John Wiley \& Sons Inc.

Perlman, D. \& Peplau, L. A. (1998). Loneliness. Encyclopedia of mental health,(pp.571-581). San Diego CA: Academic Press.

Person, B., Bartholomew, L. K., Addiss, D., \& van den Borne, B. (2007). Disrupted social connectedness among Dominican women with chronic filarial lymph edema. Patient Education and Counseling, 68(3), 279-286.

Raja, S. N., McGee, R., \& Stanton, W. R. (1992). Perceived attachments to parents and peers and psychological well-being in adolescence. Journal of youth and adolescence, 21(4), 471-485.

Rapee, R. M. \& Heimberg, R. G. (1997). A cognitive-behavior model of anxiety in social phobia. Behavior Research Therapy,35, 741-756.

Reiss, S., \& Valenti-Hein, D., (1990). Development of a psychopathology rating scale for children with mental retardation. Journal of Consulting and Clinical Psychology, 62, 28-33.

Resnick, M. D., Harris, L. J., \& Blum, R. W. (1993). The impact of caring and connectedness on adolescent health and well-being. Journal of Paediatrics and Child Health, 29(s1).

Rew, L., Taylor-Seehafer, M., Thomas, N. Y., \& Yockey, R. D. (2001). Correlates of resilience in homeless adolescents. Journal of Nursing Scholarship, 33(1), 33-40.

Roger, C. R. (1961). The loneliness of contemporary man as seen in the case of Ellen West. Annals of Psychotherapy, 2, 22-27.

Robinson, J. D. (2010). How do negative evaluation sensitivity, anxiety sensitivity, and expectancy combine to determine fear in people who stutter and people who do not stutter? (Master's Thesis, Wichita State University). Retrieved from http://webs.wichita.edu/debttoolsmemberfiles/csd/Research/thesis robinson.pdf

Russell, D. W. (1996). UCLA Scale (Version 3): Reliability, validity, and factor structure. Journal of Personality Assessment, 66(1), 20-40.

Russell, D., Cutrona, D., Rose, J., \& Yurko, K. (1984). Social and emotional loneliness: An examination of Weiss's typology of loneliness. Journal of Personality and Social Psychology, 46, 1313-1321.

Russell, D., Peplau, L. A., \& Cutrona, C. E. (1980). The Revised UCLA Loneliness Scale: Concurrent and discriminating validity evidence. Journal of Personality and Social Psychology, 39, 472-480.

Russell, D., Peplau, L. A., \& Ferguson, M. L. (1978). Developing a measure of loneliness. Journal of Personality Assessment, , 290-294.

Sermat, V. (1980). Some situational and personality correlates of loneliness. In J. Hartog, J. R. Audy, \& Y. A. Cohen (Eds.), The anatomy of loneliness (pp. 305-318). New York: International Universities Press.

Şar, A. H., Göktürk, G. Y., Tura, G., \& Kazaz, N. (2012). Is the Internet use an effective method to cope with elderly loneliness and decrease loneliness symptom? Procedia-Social and Behavioral Sciences, 55, 10531059.

Sandfield.A., Percy, \& Carol (2003). Accounting for single status: Heterosexism and ageism in heterosexual women's talk about marriage. Feminism \& Psychology, 13(4), 475-488.

Scheier, M. F., \& Carver, C. S. (1992). Effects of optimism on psychological and physical well-being: Theoretical overview and empirical updates. Cognitive Therapy and Research, 16(2), 201-228. http://dx.doi.org/10.1007/BF01173489

Scheier, M. F., \& Carver, C. S. (1985). Optimism, coping and health: Assessment and implication of generalized outcome experiences, Health Psychology, 4, 219-2477.

Seligman, M. E. P. (2007). Coaching and positive psychology. Australian psychologist, 42(4), 266-267.

Singh, A., \& Misra, N. (2009). Loneliness, depression and sociability in old age. Industrial Psychiatry Journal, 18, 51-55.

Smithson, K. L. (2011). The relationship among social connectedness, meaning in life, and wellness for adult women in Levinson's mid-life transition stage.

Sullivan, H. S. (1953). The Interpersonal theory of psychiatry. New York: Norton.

Stephan, W., Stephan, A., \& Palmer, R. (2008). The relationship of fear of negative evaluation and perfectionism in college students. Undergraduate Research Journal for the Human Scienec, 7. Retrieved from http://www.kon.org/ure/v7/stephan.html

Tatlilioglu, K. (2013). The effect of cognitive behavioral oriented psycho education program on dealing with loneliness: An online psychological counseling approach. Education, 134(1), 101-109.

Teachma, B. A., \& Allen, J. P. (2007). Development of social anxiety: Social interaction predictors of implicit and explicit fear of negative evaluation. Journal of Abnormal Child psychology, 35(1), 63-78.

Trathen, D. (2015). Characteristics of optimists. Retrieved from http://drtrathen.com/2014/01/30/12characteristics-of-optimics/

Turkum, A. (2005). Do optimism, social network richness, and submissive behaviors predict well-being? Study with a Turkish sample. Social Behavior and Personality: An international journal, 33(6), 619-628. DOI: https://doi.org/10.2224/sbp.2005.33.6.619

Vagos, P., Salvador, M. D. C., Rijo, D., Santos, I. M., Weeks, J. W., \&Heimberg, R. G. (2016). Measuring 
evaluation fears in adolescence: psychometric validation of the Portuguese versions of the fear of positive evaluation scale and the specific fear of negative evaluation scale. Measurement and Evaluation in Counseling and Development, $49(1), 46-62$.

Vanderhorst, R. K., \& McLaren, S. (2005). Social relationships as predictors of depression and suicidal ideation in older adults. Aging \& mental health, 9(6), 517-525.

Vecchione, M., Alessandri, G., Caprara, G. V., \&Tisak, J. (2014). Are method effects permanent or ephemeral in nature? The case of the Revised Life Orientation Test. Structural Equation Modeling: A Multidisciplinary Journal, 21(1), 117-130.

Vincke, J., \& Van Heeringen, K. (2002). Confidant support and the mental wellbeing of lesbian and gay young adults: A longitudinal analysis. Journal of Community \& Applied Social Psychology, 12(3), 181-193.

Watson, D; R Friend (1969). Measurement of Social-evaluative Anxiety. Journal of Consulting and Clinical Psychology. 33 (4): 448-57

Weiss, R. S. (1973). The experiences of emotional and social isolation. Cambridge, Mass: MIT Press. 


\section{APPENDICES}

Informed Consent Form

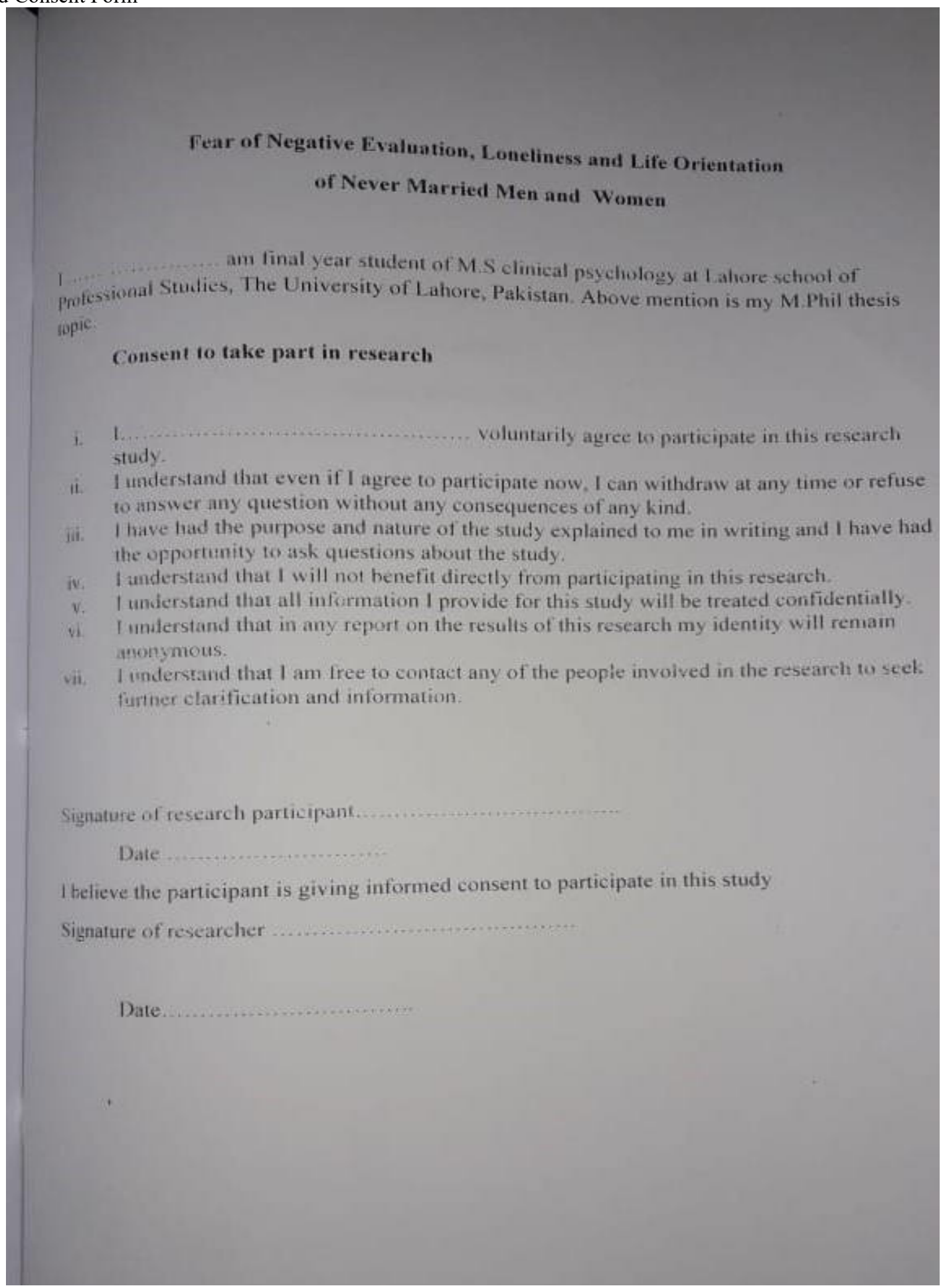

\section{Demographic Form}

Sr.

Age.............

Gender..................

Family structure.

Income. 


\section{Questionnaire}

\section{Fear of Negative Evaluation}

This questionnaire is composed of 30 statements regarding your confidence with other people. Circle YES if you consider that the statement if true of your feelings most of the time. Circle NO if you consider that the statement is rarely true of you. Remember that this information is completely confidential.

\begin{tabular}{|c|c|}
\hline & Please circle \\
\hline I rarely worry about seeming foolish to others & YES \\
\hline I worry about what people will think of me even when I know it doesn't make any difference & YES \\
\hline I become tense and jittery if I know that someone is sizing me up & YES \\
\hline I am unconcerned even if I know that people are forming an unfavourable impression of me & YES \\
\hline I feel very upset when I commit some social error & YES \\
\hline The opinions that people have of me cause me little concern & YES \\
\hline I am often afraid that I may look ridiculous or make a fool of myself & YES \\
\hline I react very little when other people disapprove of me & YES \\
\hline I am frequently afraid of other people noticing my shortcomings & YES \\
\hline The disapproval of others would have little effect on me & YES \\
\hline If someone is evaluating me I expect the worst & YES \\
\hline I rarely worry about what kind of impression I am making on someone & YES \\
\hline I am afraid that others will not approve of me & YES \\
\hline I am afraid that others will find fault with me & YES \\
\hline Other people's opinions of me do not bother me & YES \\
\hline I am not necessarily upset if I do not please someone & YES \\
\hline When I am talking to someone, I worry about what they may be thinking of me & YES \\
\hline I feel that you can't help making social errors sometimes, so why worry about it & YES \\
\hline I am usually worried about what kind of impression I make & YES \\
\hline I worry a lot about what my superiors think of me & YES \\
\hline If I know someone is judging me, it has little effect on me & YES \\
\hline I worry that others will think I am not worthwhile & YES \\
\hline Sometimes I am too concerned with what other people may think of me & YES \\
\hline I often worry that I will say or do the wrong things & YES \\
\hline I am often indifferent to the opinions others have of me & YES \\
\hline I am usually confident that others will have a favourable impression of me & YES NO \\
\hline I often worry that people who are important to me won't think very much of me & YES \\
\hline I brood about the opinions my friends have about me & YES NO \\
\hline I become tense and jittery if I know I am being judged by my superiors & YES \\
\hline
\end{tabular}

\section{Life Orientation Scale}

Please be as honest and accurate as you can throughout. Try not to let your response to one statement influence your responses to other statements. There are no "correct" or "incorrect" answers. Answer according to your own feelings, rather than how you think "most people" would answer.

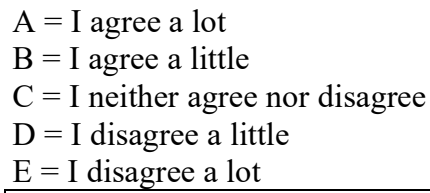

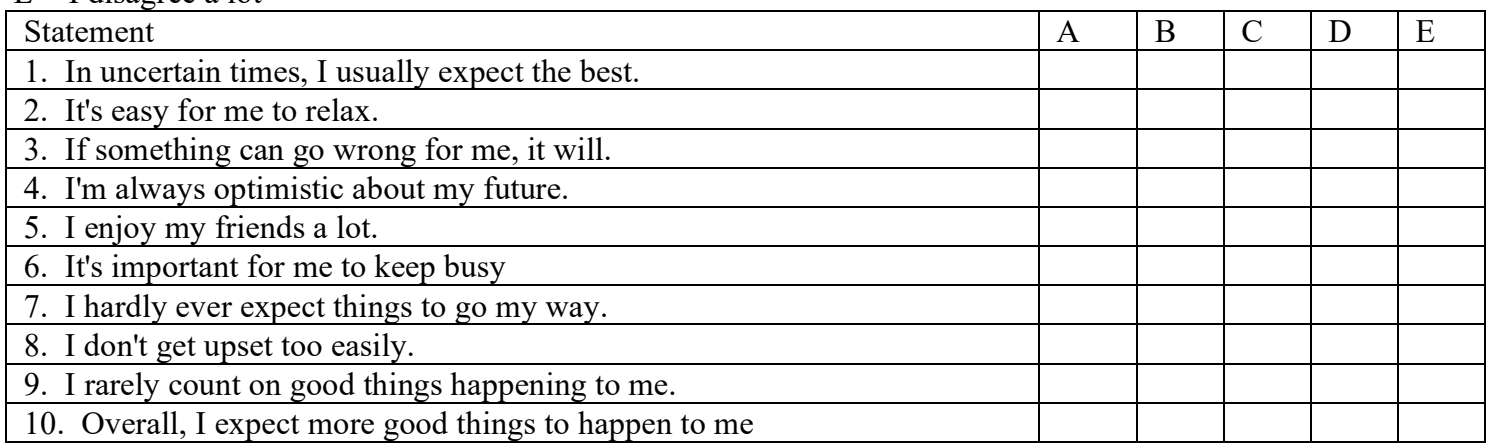




\section{UCLA Loneliness Scale}

INSTRUCTIONS: Indicate how often each of the statements below is descriptive of you.

C indicates "I often feel this way"

$\mathrm{S}$ indicates "I sometimes feel this way"

$\mathrm{R}$ indicates "I rarely feel this way" $\mathrm{N}$ indicates "I never feel this way"

\begin{tabular}{|c|c|c|c|c|}
\hline 1. I am unhappy doing so many things alone & $\mathrm{O}$ & $\mathrm{S}$ & $\mathrm{R}$ & $\mathrm{N}$ \\
\hline 2. I have nobody to talk to & & & & \\
\hline 3. I cannot tolerate being so alone & & & & \\
\hline 4. I lack companionship & & & & \\
\hline 5. I feel as if nobody really understands me & & & & \\
\hline 6. I find myself waiting for people to call or write & & & & \\
\hline 7. There is no one I can turn to & & & & \\
\hline 8. I am no longer close to anyone & & & & \\
\hline 9. My interests and ideas are not shared by those around me & & & & \\
\hline 10. I feel left out & & & & \\
\hline 11. I feel completely alone & & & & \\
\hline 12. I am unable to reach out and communicate with those around me & & & & \\
\hline 13. My social relationships are superficial & & & & \\
\hline 14. I feel starved for company & & & & \\
\hline 15. No one really knows me well & & & & \\
\hline 16. I feel isolated from others & & & & \\
\hline 17. I am unhappy being so withdrawn & & & & \\
\hline 18. It is difficult for me to make friends & & & & \\
\hline 19. I feel shut out and excluded by others & & & & \\
\hline 20. People are around me but not with me & & & & \\
\hline
\end{tabular}

